\title{
Parental urinary biomarkers of preconception exposure to bisphenol A and phthalates in relation to birth outcomes
}

Melissa M. Smarr ${ }^{1 *}$, Katherine L. Grantz ${ }^{1}$ Rajeshwari Sundaram¹, José M. Maisog ${ }^{1}$, Kurunthachalam Kannan² and Germaine M. Buck Louis ${ }^{1}$

\begin{abstract}
Background: Bisphenol A (BPA) and phthalates are ubiquitous non-persistent endocrine disrupting chemicals whose relation with infant birth size is not clearly understood.

Methods: We examined associations between maternal and paternal preconception urinary concentrations of total BPA and 14 phthalate metabolites and birth size for 233 infants. Multiple linear regression models were used to estimate parental quartiles of BPA and phthalates in relation to birth weight, length, head circumference, and ponderal index with separate models run for each parent adjusting for age, smoking, body mass index, education, alcohol, parity, and creatinine. Models also included an interaction term for each chemical and infant sex and were further adjusted to include the other partner's chemical concentrations.
\end{abstract}

Results: In maternal models adjusted for partner's exposure and covariates, reductions in birth weight (range: $178-215 \mathrm{~g} ; p<0.05)$ were observed for the $2^{\text {nd }}$ quartile of maternal monomethyl phthalate, mono-[(2-carboxymethyl) hexyl] phthalate and mono-n-octyl phthalate when compared with the $1^{\text {st }}$ quartiles. The $3^{\text {rd }}$ quartile of monoethylhexyl phthalate (mEHP) was also associated with a $200.16 \mathrm{~g}$ (95 \% Cl: -386.90, -13.42) reduction. Similar reductions in birth weight were observed for the $2^{\text {nd }}$ quartile of paternal mEHP ( $\left.\beta=-191.93 \mathrm{~g} ; 95 \% \mathrm{Cl}:-381.61,-2.25\right)$. Additionally, select maternal urinary metabolites were associated with decreased head circumference, birth length and gestational age. However, paternal concentrations were generally associated with increased birth length and gestational age.

Conclusions: We observed some suggestion that preconception maternal and paternal urinary concentration of BPA and specific phthalate metabolites may be associated with smaller birth size and increased gestational age, though the findings appeared to be parent and chemical specific.

Keywords: Bisphenol A, Phthalates, Preconception exposure, Birth weight, Head circumference, Ponderal index, Endocrine disruptors

\section{Background}

Bisphenol A (BPA) and phthalates are non-persistent endocrine disrupting chemicals (EDCs) found in a variety of commercial products. Specifically, BPA is used in the production of polycarbonate plastics and epoxy resins, e.g., plastic bottles, lining of food cans, and thermal receipt papers [1]. Similarly, phthalates are

\footnotetext{
* Correspondence: melissa.smarr@mail.nih.gov

'Division of Intramural Population Health Research, Eunice Kennedy Shriver National Institute of Child Health and Human Development, National Institutes of Health, 6100 Executive Blvd, Rockville, MD 20852, USA Full list of author information is available at the end of the article
}

plasticizers found in many consumer products, including but not limited to cosmetics, children's toys, pharmaceuticals and nutritional supplements [2]. Biomonitoring data underscore their ubiquitous prevalence, with $93 \%$ and $75 \%$ of the U.S. general population having detectable concentrations of BPA and phthalates, respectively $[3,4]$. In an analysis of urine samples collected on a subset of pregnant women from the 2003-2004 National Health and Nutritional Examination Survey (NHANES), BPA was detected in $96 \%$ of the samples and phthalates were detected in $99-100 \%$ of the samples [5]. Therefore, 
continual human exposure is probable, and the assessment of possible human health effects is essential.

Despite a suggestive body of animal evidence, current reviews conclude that studies on BPA and human health are limited [6-8]. An evolving body of epidemiologic research suggests that BPA may adversely affect human fecundity as measured by diminished semen quality [9], early blastocyst or embryonic development [10] and reduced levels of estradiol and number of oocytes retrieved [11] among women undergoing assisted reproductive technologies. Regarding pregnancy outcomes, maternal exposures have been associated with increased odds of preterm birth [12], reductions in length of gestation [13-15], birth weight, length [16] and fetal growth [17], suggesting a relation between parental exposures and fetal development.

To date, research has largely relied upon prenatal urinary concentrations and associated fetal/infant outcomes. To our knowledge, there have been no previous efforts focusing on parental preconception exposures to BPA and phthalates, despite the couple dependent nature of pregnancy. Such a study is important for helping to more fully understand the implications of physiological changes during pregnancy that may be associated with the reported variability of chemical exposures during this sensitive window of human development [18]. As such, preconception concentrations may be more reflective of early pregnancy concentrations that characterize women before they are typically recruited into pregnancy cohort studies. To date, few studies have focused on parental preconception or early pregnancy exposures other than a few focusing on persistent chemicals reported to be associated with infant birth size outcomes [19-21]. Other authors have noted the importance of considering paternal exposures given their ability to either directly impact sperm DNA or indirectly through seminal fluid exposure [22]. Prompted by these data gaps, we undertook an investigation of parental preconception BPA and phthalate exposures in relation to prospectively measured gestation and birth size, including the joint analysis of parental exposures.

\section{Materials and methods}

\section{Study design and subjects}

The study population comprises 501 reproductive aged couples who were recruited from 16 counties in Michigan and Texas between 2005 and 2009 with the explicit purpose of assessing environmental influences on human fecundity and fertility, as previously described [23]. Couples were recruited upon discontinuing contraception for purposes of becoming pregnant. Inclusion criteria were minimal: females aged $18-40$ and males $\geq 18$ years; in a committed relationship; no physician diagnosis of infertility/sterility; females had to have menstrual cycles between 21-42 days without any injectable hormonal contraceptives in the past year; and an ability to communicate in English or Spanish. In-person interviews were conducted with each partner of the couple to ascertain lifestyle and reproductive history followed by standard anthropometric assessments to assess body mass index (BMI) [24]. Couples were followed for up to a year while trying for pregnancy, and women used home pregnancy test kits on the day of expected menstruation for the detection of pregnancy.

Among the 501 enrolled couples, 347 (69 \%) had an observed human chorionic gonadotropin confirmed pregnancy of which $90 \%$ occurred within 6 menstrual cycles and the remaining $10 \%$ in cycles 7-12 [25]. Furthermore, $233(67 \%)$ had a singleton live birth, with a reported birth weight (exclusions for the present analysis included 2 couples with twin live births and 1 couple with a twin gestation and a singleton live birth). Pregnant women were followed daily through six postconception weeks, then monthly until either a pregnancy loss or delivery. Institutional review board approvals were obtained from all collaborating institutions; couples gave written informed consent prior to study participation.

\section{Biospecimens collection and exposure assessment}

During the enrollment home visit, research assistants instructed couples in the proper collection of urine samples for the quantification of BPA, phthalates, and creatinine. Samples were transported on ice for processing and shipment to the laboratory. Chemical analysis was performed at the Wadsworth Center, New York State Department of Health using an established protocol [26]. Specifically, urinary concentrations of total BPA were quantified as nanograms/milliliter $(\mathrm{ng} / \mathrm{mL})$ by enzymatic deconjugation, solid phase extraction and high-performance liquid chromatography (HPLC), coupled with API 2000 electrospray triple-quadrupole mass spectrometry (MS/MS). Urinalysis was performed using HPLC-MS/MS and an established protocol [27] for 14 phthalate metabolites: monomethyl phthalate (mMP), monoethyl phthalate (mEP), mono-n-butyl phthalate (mBP), mono (2-isobutyl phthalate) (miBP), monobenzyl phthalate (mBzP), mono (2-ethyl-5-carboxyphentyl) phthalate (mECPP), mono-[(2-carboxymethyl) hexyl] phthalate (mCMHP), mono (2-ethyl-5-oxohexyl) phthalate (mEOHP), mono (2-ethyl-5-hydroxyhexyl) phthalate (mEHHP), mono (2-ethylhexyl) phthalate (mEHP), mono (3-carboxypropyl) phthalate (mCPP), monocyclohexyl phthalate (mCHP), mono-isononyl phthalate (mNP), and monooctyl phthalate (mOP). Creatinine was quantified using a Roche/Hitachi Model 912 clinical analyzer (Dallas, TX) and the Creatinine Plus Assay. In addition, non-fasting blood samples were collected from each partner to 
measure serum cotinine using liquid chromatographyisotope dilution tandem mass spectrometry and as reported in $\mathrm{ng} / \mathrm{mL}[28]$.

\section{Assessment of birth size}

Following delivery, couples returned standardized birth announcements that were included in the pregnancy journals women completed while pregnant. This data collection form was designed for parents to report date-of-delivery, infant sex, birth weight in pounds and ounces $(n=233)$; length in -inches $(n=230)$; head circumference in inches $(n=183)$; and date of delivery $(n=233)$. Weight was converted to grams, and length and head circumference to centimeters for analysis. Gestational age was defined as the number of days from the day of ovulation as recorded on fertility monitors that was estimated to be the day of conception and date of delivery. We also estimated ponderal indices (PIs) for 230 infants, which is similar to adult body mass index and derived from the following formula: [birth weight (grams)/birth length $\left.\left(\mathrm{cm}^{3}\right)\right] \times 100$. PIs are proxies of infant adiposity and can be further categorized in relation to growth symmetry: normal (2.20-3.00), symmetrical $(>3.00)$ and asymmetrical $(<2.20)$ [29].

\section{Statistical analysis}

Univariate analyses were performed to assess all chemical distributions and birth size outcomes. Machine-read values for all chemicals were used to avoid biasing regression estimates [30,31]. Serum cotinine and urinary creatinine concentrations were natural-log transformed (ln) to approach more normal distributions. Geometric means and corresponding $95 \%$ confidence intervals were estimated on ln-transformed chemical concentrations. We modeled all chemical data in quartiles in light of the non-normal distributions, absence of known linear relations with birth size and to aid in the interpretation of findings. To minimize possible bias associated with excluding individuals with missing data while maintaining power, we imputed data for missing chemical exposures stemming from insufficient urine for quantification and relevant covariates $(10 \%)$ using data for the entire cohort and Markov Chain Monte Carlo methods, under an assumption of 'missing at random' [32, 33]. We defined statistical significance as a two-sided $p$-value $<0.05$.

Multiple linear regression models were used to estimate the mean change in each birth outcome per quartile of urinary chemical concentrations, relative to the lowest quartile; birth outcomes were modeled separately for each chemical and parent. Models were adjusted $a$ priori for creatinine $(\mathrm{ng} / \mathrm{mL})$, age (years), race/ethnicity, body mass index (weight in $\mathrm{kg} /$ height in $\mathrm{m}^{2}$ ), education, smoking (serum cotinine $\mathrm{ng} / \mathrm{mL}$ ), frequency of alcoholic beverage consumption, maternal parity (number of live births) conditioned on gravidity (number of pregnancies) and infant gender. Models were re-run to test for potential interactions between each chemical and infant sex in light of data suggesting possible gender susceptibilities $[34,35]$. Finally, models were further adjusted for the other partner's chemical concentration, smoking and creatinine in light of pregnancy being a couple-dependent outcome. Testing for trend was conducted based on the linear trends of the association between BPA and phthalate urinary biomarker concentrations across the four intervals defined by their quartiles and the various birth outcomes. We determined a significant linear trend based on a two-sided $p$-value $<0.05$. All analyses were performed using SAS software (version 9.4; SAS Institute, Cary, NC).

\section{Results}

The cohort comprised mostly non-Hispanic White men and women who were college educated. The mean female and male ages were $29.8 \pm 3.7$ and $31.5 \pm 4.6$ years, respectively (Table 1). Prevalence of smoking and alcohol use at baseline was higher among males than females (10\% vs $4 \%$ and $87 \%$ vs $78 \%$, respectively). The cohort was largely healthy, except the slightly higher prevalence of self-reported hypertension among males ( $8 \%$ vs $3 \%$ ). However, histories of chronic infection and diabetes were $<1 \%$ among couples.

The geometric means and accompanying $95 \%$ CIs for urinary BPA and phthalate metabolites for each partner are displayed in Table 2. Overall, concentrations of BPA and select phthalates (mEP, mEHP, mEHHP, mECPP, $\mathrm{mCMHP}$ and $\mathrm{mCPP}$ ) were significantly higher for males than females $(p<0.05)$. Generally, the percentage of urine samples with chemical concentrations below the limit of detection (LOD) were uniform across parental sex, with the exception of two chemicals, mMP and mEHP, which were more readily detectible in male than female urine samples (Table 2). Additionally, we assessed the correlation coefficients for maternal and paternal urinary BPA concentrations $(r=0.25)$, and the range of correlation coefficients for the various phthalate metabolites were between -0.03 to $r=0.33$.

Birth outcomes were not statistically different by infant sex, with the exception of birth weight (see Additional file 1). Mean birth weight was $3313.7 \pm 447.1 \mathrm{~g}$ among girls and $3445.0 \pm 488.7 \mathrm{~g}$ among boys $(p=0.03)$. Although not statistically significant, the lower end of the range of gestational age at birth was higher among girls (173-290 days) compared with boy infants (155-296). Additional details are provided in Additional file 1.

\section{Maternal urinary chemicals and birth outcomes}

Overall, maternal biomarkers of preconception exposures to non-persistent EDCs did not have a strong 
Table 1 Socio-demographic comparison of partners with a singleton live birth $(n=233){ }^{a}$, LIFE Study

\begin{tabular}{|c|c|c|}
\hline Characteristic & Mothers & Fathers \\
\hline Age (years): mean $\pm \mathrm{SD}^{\dagger}$ & $29.8 \pm 3.7$ & $31.5 \pm 4.6$ \\
\hline Body mass index (kg/m2): mean $\pm \mathrm{SD}^{+}$ & $26.4 \pm 6.6$ & $28.9 \pm 4.7$ \\
\hline \multicolumn{3}{|l|}{ Race/Ethnicity: n (\%) } \\
\hline Non-Hispanic White & $194(84.0)$ & $197(84.9)$ \\
\hline Non-Hispanic Black & $2(0.9)$ & $4(1.7)$ \\
\hline Hispanic & $20(8.7)$ & $20(8.6)$ \\
\hline Other & $15(6.4)$ & $11(4.8)$ \\
\hline \multicolumn{3}{|l|}{ Education: n (\%) } \\
\hline$<$ High school & $0(0)$ & $2(0.9)$ \\
\hline High school & $9(3.9)$ & $5(2.2)$ \\
\hline College & $222(96.1)$ & $224(97.8)$ \\
\hline \multicolumn{3}{|l|}{ Smoking status: n (\%) ${ }^{\dagger}$} \\
\hline Active (cotinine $\geq 100$ ng/ml) & $11(4.7)$ & $24(10.3)$ \\
\hline Passive (cotinine < 100 ng/ml) & $222(95.3)$ & $209(89.7)$ \\
\hline \multicolumn{3}{|l|}{ Alcohol use: $n(\%)^{\dagger}$} \\
\hline No & $52(22.3)$ & $31(13.3)$ \\
\hline Yes & $181(77.7)$ & $201(86.7)$ \\
\hline \multicolumn{3}{|l|}{ History of diabetes: n (\%) } \\
\hline No & $232(99.6)$ & $232(99.6)$ \\
\hline Yes & $1(0.4)$ & $1(0.4)$ \\
\hline \multicolumn{3}{|l|}{ History of hypertension: n (\%) } \\
\hline No & $226(97.0)$ & $213(91.8)$ \\
\hline Yes & $7(3.0)$ & $19(8.2)$ \\
\hline \multicolumn{3}{|l|}{ History of chronic infections: n (\%) } \\
\hline No & 232 (99.6) & 232 (99.6) \\
\hline Yes & $1(0.4)$ & $1(0.4)$ \\
\hline
\end{tabular}

${ }^{a}$ Missing covariate data is not reflected in this table

${ }^{\dagger} p<0.05$ from independent $t$-test for continuous characteristics or chi-square test for categorical characteristics

linear association with measures of birth size. Maternal preconception urinary levels of BPA were not associated with any birth size outcomes (see Additional file 2). However, specific urinary levels for 8 out of 14 phthalates were significantly associated with decrements in birth size outcomes; importantly, no associations were observed for 6 of the 14 phthalates (Table 3). Most notably, negative associations were observed between phthalate metabolites of low molecular weight maternal compounds and birth weight. In adjusted models including the sum of paternal chemicals, for the $2^{\text {nd }}$ versus $1^{\text {st }}$ quartile of urinary mMP mean birth weight was reduced by $177.6 \mathrm{~g}$ (95 \% CI: -344.9, -10.3). Likewise, for mothers in the $2^{\text {nd }}$ versus $1^{\text {st }}$ quartile of mEP a $200.2 \mathrm{~g}$ (95 \% CI: -386.9, -13.4) decrease in birth weight was observed for infants. Overall, no associations were seen for birth length with one exception. Specifically, when comparing mothers in the $2^{\text {nd }}$ and $3^{\text {rd }}$ quartiles versus the $1^{\text {st }}$ quartile of mMP urinary concentrations a reduction in birth length was observed $(\beta=-1.45 \mathrm{~cm}$; $95 \% \mathrm{CI}:-2.8,-0.1$ and $\beta=-1.57 \mathrm{~cm} ; 95 \% \mathrm{CI}:-2.6$, -0.5 , respectively) (Table 3 ). See Additional file 2 for all associations between maternal urinary concentrations and birth size outcomes not achieving statistical significance

Several phthalates were associated with reductions in head circumference. Infants whose mothers had concentrations in the $3^{\text {rd }}$ versus $1^{\text {st }}$ quartile for $\mathrm{mEP}$ and $\mathrm{mEOHP}$ had smaller head circumference $(\beta=-1.4 \mathrm{~cm} ; 95 \% \mathrm{CI}$ : $-2.3,-0.6$ and $\beta=-1.3 \mathrm{~cm}$; $95 \% \mathrm{CI}:-2.2,-0.4$, respectively) (Table 3). Increasing maternal exposure to Di-2-ethylhexyl phthalate (DEHP), as measured by the monoester metabolite mECPP, was also associated with reduced head circumference $(\beta=-0.93 \mathrm{~cm} ; 95 \% \mathrm{CI}:-1.8,-0.06)$, when comparing women in the 2 nd versus $1^{\text {st }}$ quartile. None of the chemicals were significantly associated with ponderal indices when modeling maternal concentrations, including when further adjusting for paternal concentrations.

Finally, maternal preconception urinary phthalate metabolites were predominantly negatively associated with gestational age at birth. The $2^{\text {nd }}$ quartile of low molecular weight metabolite mMP, previously described, was associated with a 5.5 day (95\% CI: -10.0, -1.0) shorter gestational age, compared with the $1^{\text {st }}$ quartile (Table 3). Contrarily, when comparing infants whose mothers were in the $3^{\text {rd }}$ versus $1^{\text {st }}$ quartile of $\mathrm{mEHP}$, a longer gestational age ( $\beta=5.7$ days; $95 \% \mathrm{CI}$ : $0.5,10.8)$ was observed. With regard to high molecular weight phthalate metabolites, the $2^{\text {nd }}$ versus $1^{\text {st }}$ quartile of mOP was negatively associated with gestational age ( $\beta=-5.2$ days; $95 \% \mathrm{CI}$ : $-9.9,-0.4)$. Additionally, comparing the $4^{\text {th }}$ and $1^{\text {st }}$ quartiles of maternal mNP reflected a significant 7 - day $(95 \% \mathrm{CI}$ : $-12.3,-1.6)$ reduction in gestational age. A significant $(p=0.02)$ trend was observed between increasing quartiles of $\mathrm{mNP}$ and mean change in gestational age (Table 3 ).

\section{Paternal urinary chemicals and birth outcomes}

With regard to paternal urinary phthalate concentrations, few negative associations were observed in the adjusted analysis, though different chemicals emerged. Paternal $2^{\text {nd }}$ quartile of mEHP concentrations were associated with reduced birth weight when compared with the $1^{\text {st }}$ quartile $(\beta=-191.9 \mathrm{~g} ; 95 \% \mathrm{CI}:-381.6,-2.3)$ (Table 4). Conversely, comparing the highest and the lowest quartiles of paternal $\mathrm{mCHP}$, a positive association was observed with birth weight ( $\beta=224.5$ g; $95 \%$ CI: 33.9, 415.0). An overall significant $(p=0.02)$ trend was observed between increasing paternal quartiles of urinary $\mathrm{mCHP}$ and mean change in birth weight. 
Table 2 Geometric means (95\% Cl) for maternal and paternal preconception urinary metabolite concentrations

\begin{tabular}{|c|c|c|c|c|c|c|c|c|}
\hline \multirow[b]{2}{*}{ Chemical (ng/mL) } & \multicolumn{4}{|c|}{ Maternal urinary concentrations $(n=213)$} & \multicolumn{4}{|c|}{ Paternal urinary concentrations $(n=211)$} \\
\hline & LOD (ng/mL) & $\%<\mathrm{LOD}$ & $\%$ Negative & Geometric mean $(95 \% \mathrm{Cl})$ & $\%<\mathrm{LOD}$ & $\%$ Negative & Geometric mean $(95 \%$ Cl) & $p^{a}$ \\
\hline Creatinine & 3.5 & 4.3 & 4.3 & $62.53(55.7-70.2)$ & 4.7 & 4.7 & $116(106-128)$ & $<0.001$ \\
\hline BPA & 0.02 & 11 & 9.4 & $0.38(0.31-0.45)$ & 11 & 11 & $0.59(0.49-0.71)$ & 0.00 \\
\hline \multicolumn{9}{|c|}{ Low molecular weight } \\
\hline $\mathrm{mMP}$ & 1.0 & 74 & 34 & $0.57(0.44-0.76)$ & 67 & 34 & $0.82(0.64-1.07)$ & 0.11 \\
\hline mEP & 0.2 & 9.4 & 9.4 & $62.6(50.3-77.9)$ & 10 & 10 & $98.5(78.4-124)$ & 0.01 \\
\hline $\mathrm{mBP}$ & 0.2 & 9.8 & 9.4 & $3.29(2.75-3.94)$ & 11 & 10 & $6.87(5.76-8.19)$ & 0.49 \\
\hline miBP & 0.2 & 12 & 11 & $6.13(5.15-7.29)$ & 12 & 10 & $3.85(3.27-4.54)$ & 0.10 \\
\hline \multicolumn{9}{|l|}{ DEHP metabolites } \\
\hline mEHP & 1.0 & 64 & 60 & $3.92(2.90-5.31)$ & 54 & 49 & $4.54(3.39-6.08)$ & 0.02 \\
\hline mEHHP & 0.2 & 11 & 9.8 & $9.18(7.56-11.1)$ & 11 & 11 & $14.7(11.8-18.2)$ & 0.00 \\
\hline mEOHP & 0.2 & 13 & 9.8 & $5.15(4.13-6.42)$ & 11 & 10 & $7.03(5.67-8.70)$ & 0.09 \\
\hline mECPP & 0.2 & 11 & 9.4 & $13.4(10.9-16.4)$ & 10 & 10 & $18.9(15.4-23.1)$ & 0.02 \\
\hline mCMHP & 0.2 & 9.8 & 9.4 & $9.38(7.72-11.4)$ & 11 & 11 & $18.9(15.36-23.3)$ & 0.00 \\
\hline \multicolumn{9}{|c|}{ High molecular weight } \\
\hline $\mathrm{mBzP}$ & 0.2 & 13 & 9.8 & $2.90(2.37-3.54)$ & 14 & 11 & $3.40(2.82-4.09)$ & 0.32 \\
\hline $\mathrm{mCHP}$ & 0.2 & 96 & 51 & $0.01(0.01-0.02)$ & 96 & 49 & $0.01(0.01-0.02)$ & 0.67 \\
\hline $\mathrm{mOP}$ & 0.5 & 97 & 69 & $0.06(0.04-0.08)$ & 97 & 71 & $0.07(0.04-0.10)$ & 0.51 \\
\hline mCPP & 0.2 & 14 & 9.8 & $3.12(2.52-3.86)$ & 14 & 11 & $5.47(4.47-6.70$ & 0.00 \\
\hline mNP & 0.5 & 96 & 57 & $0.07(0.05-0.09)$ & 95 & 50 & $0.08(0.06-0.11)$ & 0.09 \\
\hline
\end{tabular}

Abbreviations: BPA bisphenol (A; $M M P$ monomethyl phthalate, $m E P$ monoethyl phthalate, $m B P$ mono-n-butyl phthalate, miBP monoisobutyl phthalate, $m E H P$ monoethylhexyl phthalate, $m E H H P$ mono-(2-ethyl-5-hydroxyhexyl) phthalate, $m E O H P$ mono-(2-ethyl-5-oxohexyl) phthalate, $m E C P P$ mono-(5-carboxy-2-ethylpentyl) phthalate, $m C M H P$ mono-[(2-carboxymethyl)hexyl] phthalate, $m B z P$ monobenzyl phthalate, $m C H P$ monocyclohexyl phthalate, $m O P$ mono-n-octyl phthalate, $m C P P$ mono(3-carboxypropyl) phthalate, $m N P$ monoisononyl phthalate

${ }^{a}$ Reported $p$-values are from Wilcoxon-Mann-Whitney tests comparing the geometric means of maternal and paternal urinary chemical concentrations

In contrast to the observations based upon maternal urinary concentrations, the highest quartile of paternal urinary BPA concentration was positively associated with birth length $(\beta=1.4 \mathrm{~cm} ; 95 \% \mathrm{CI}: 0.3,2.5)$ (Table 4). The overall trend also was observed to be significant $(p=0.02)$ between increasing quartiles of paternal BPA and mean change in birth length (Table 4). A reduction in birth length was observed only between the $2^{\text {nd }}$ versus $1^{\text {st }}$ paternal quartile of $\operatorname{mOP}(\beta=-1.2 \mathrm{~cm}$; $95 \%$ CI: $-2.3,-0.1)$. No associations were observed between paternal urinary chemicals and either head circumference or ponderal index. However, urinary phthalate metabolites were positively associated with gestational age. Specifically, the $2^{\text {nd }}$ and $3^{\text {rd }}$ quartiles of paternal mEOHP relative to the $1^{\text {st }}$ quartile were associated with a longer gestational age $(\beta=7.2$ days; $95 \%$ CI: 2.4, 12.1 and $\beta=5.1$ days; $95 \%$ CI: 0.02 , 10.3 , respectively, $\mathrm{p}$ for trend $=0.22$ ). Likewise, the $2^{\text {nd }}$ and $4^{\text {th }}$ quartiles of $\mathrm{mECPP}$ were associated with a longer gestational age ( $\beta=7.3$ days; $95 \%$ CI: 2.0 , 12.7 and $\beta=6.4$ days; $95 \%$ CI: $0.3,12.5$, respectively, $p$ for trend $=0.04$ ). Finally, the $4^{\text {th }}$ quartile of paternal urinary concentrations of high molecular weight metabolite $\mathrm{mCHP}$ was associated with a 7.0 day
(95 \% CI $=2.2,11.9)$ increase in gestational age, compared with the lowest quartile; an overall trend was observed for mean change in gestational age with increasing urinary levels of $\mathrm{mCHP}$ ( $\mathrm{p}$ for trend $=0.005$ ). Findings for paternal chemical concentrations and birth outcomes not achieving significance are provided in Additional file 3.

\section{Discussion}

In this analysis of couples' preconception urinary concentrations of short-lived endocrine disrupting chemicals and infant birth outcomes, we found parental urinary biomarkers for BPA and phthalates to be predominantly associated with reductions in length of gestation and birth size in a non-linear manner. While many signals of association were observed for specific quartiles of urinary EDCs, an overall linear trend between increasing biomarker quartiles and mean change in birth outcomes was only observed for 4 of the 15 chemicals and no chemical was consistently associated with reduction irrespective of parent. Specifically, we observed an overall linear trend between quartiles of maternal $\mathrm{mNP}$ and gestational age. Additionally, a linear trend was observed between quartiles of paternal BPA and birth length, 
Table 3 Associations between quartiles of maternal urinary BPA and phthalate concentrations and mean change in birth outcomes

\begin{tabular}{|c|c|c|c|c|c|}
\hline & BW (g) & $\mathrm{BL}(\mathrm{cm})$ & $\mathrm{HC}(\mathrm{cm})$ & $\mathrm{PI}\left(\mathrm{g} / \mathrm{cm}^{3}\right)$ & GA (days) \\
\hline Chemical quartiles (ng/mL) & $\beta(95 \% \mathrm{Cl})$ & $\beta(95 \% \mathrm{Cl})$ & $\beta(95 \% \mathrm{Cl})$ & $\beta(95 \% \mathrm{Cl})$ & $\beta(95 \% \mathrm{Cl})$ \\
\hline \multicolumn{6}{|l|}{ Low molecular weight } \\
\hline \multicolumn{6}{|l|}{$\mathrm{mMP}$} \\
\hline 1st $(\leq-0.004)$ & Ref. & Ref. & Ref. & Ref. & Ref. \\
\hline 2nd $(-0.001-0.33)$ & $-177.6(-344.9,-10.3)^{*}$ & $-1.6(-2.6,-0.5)^{* *}$ & $-0.3(-1.1,0.6)$ & $0.1(-0.1,0.2)$ & $-5.5(-10.0,-1.0)^{*}$ \\
\hline 3rd (0.34 - 1.68) & $-168.9(-375.7,37.9)$ & $-1.5(-2.8,-0.1)^{*}$ & $-0.4(-1.3,0.6)$ & $0.1(0.0,0.3)$ & $-3.3(-9.0,2.5)$ \\
\hline 4th $(\geq 1.69)$ & $-94.0(-280.5,92.4)$ & $-1.0(-2.1,0.1)$ & $-0.2(-1.1,0.8)$ & $0.1(-0.1,0.2)$ & $-4.2(-9.7,1.4)$ \\
\hline p-trend & 0.94 & 0.33 & 0.70 & 0.34 & 0.45 \\
\hline \multicolumn{6}{|l|}{$\mathrm{mEP}$} \\
\hline 1st $(\leq 26.9)$ & Ref. & Ref. & Ref. & Ref. & Ref. \\
\hline 2nd (27.3 - 65.3) & $-34.6(-225.4,156.2)$ & $-0.1(-1.1,1.0)$ & $-0.3(-1.1,0.5)$ & $0.0(-0.2,0.2)$ & $2.7(-2.2,7.5)$ \\
\hline 3rd (66.1 - 203) & $-200.2(-386.9,-13.4)^{*}$ & $-0.1(-1.2,0.9)$ & $-1.4(-2.3,-0.6)^{* *}$ & $-0.1(-0.3,0.1)$ & $-1.8(-6.6,2.9)$ \\
\hline 4th $(\geq 203)$ & $-72.1(-287.5,143.4)$ & $-0.3(-1.5,0.9)$ & $-0.6(-1.6,0.4)$ & $0.0(-0.2,0.2)$ & $0.6(-4.9,6.1)$ \\
\hline p-trend & 0.80 & 0.52 & 0.36 & 0.58 & 0.19 \\
\hline \multicolumn{6}{|l|}{ DEHP Metabolites } \\
\hline \multicolumn{6}{|l|}{ mEHP } \\
\hline 1st $(\leq-1.89)$ & Ref. & Ref. & Ref. & Ref. & Ref. \\
\hline 2nd (-1.88--0.000716) & $63.0(-150.4,276.3)$ & $0.2(-1.0,1.3)$ & $0.4(-0.5,1.3)$ & $0.0(-0.1,0.1)$ & $1.4(-3.8,6.6)$ \\
\hline 3rd (0.0340 - 3.73) & $139.0(-84.4,362.5)$ & $0.4(-0.6,1.4)$ & $0.4(-0.1,1.5)$ & $0.1(-0.1,0.2)$ & $5.7(0.5,10.8)^{*}$ \\
\hline 4th $(\geq 3.81)$ & $138.5(-70.7,347.6)$ & $0.4(-0.8,1.6)$ & $-0.2(-1.4,1.0)$ & $0.1(-0.1,0.2)$ & $3.6(-2.2,9.5)$ \\
\hline $\mathrm{p}$-trend & 0.09 & 0.37 & 0.81 & 0.20 & 0.10 \\
\hline \multicolumn{6}{|l|}{$\mathrm{mEOHP}$} \\
\hline 1 st $(\leq 2.02)$ & Ref. & Ref. & Ref. & Ref. & Ref. \\
\hline 2nd (2.03 - 6.14) & $-83.0(-261.7,95.8)$ & $-0.6(-1.7,0.5)$ & $-0.4(-1.3,0.5)$ & $0.1(-0.1,0.2)$ & $-0.3(-5.2,4.6)$ \\
\hline 3rd (6.15 - 15.6) & $-162.4(-350.4,25.7)$ & $-0.5(-1.7,0.8)$ & $-1.3(-2.2,-0.4)^{* *}$ & $0.0(-0.2,0.1)$ & $1.5(-3.8,6.7)$ \\
\hline 4th $(\geq 15.8)$ & $41.8(-169.8,253.5)$ & $-0.1(-1.3,1.2)$ & $-1.0(-2.0,0.1)$ & $0.1(-0.1,0.2)$ & $0.7(-5.0,6.4)$ \\
\hline p-trend & 0.43 & 0.93 & 0.18 & 0.21 & 0.56 \\
\hline \multicolumn{6}{|l|}{ mECPP } \\
\hline 1 st $(\leq 5.70)$ & Ref. & Ref. & Ref. & Ref. & Ref. \\
\hline 2nd (5.71 - 14.96) & $-154.4(-331.2,22.5)$ & $-0.5(-1.6,0.5)$ & $-0.9(-1.8,-0.1)^{*}$ & $0.0(-0.2,0.2)$ & $2.0(-2.9,6.9)$ \\
\hline 3rd (14.98 -36.3) & $-13.4(-200.3,173.5)$ & $-0.1(-1.4,1.2)$ & $-0.8(-1.7,0.2)$ & $0.0(-0.2,0.2)$ & $1.1(-4.5,6.7)$ \\
\hline 4th $(\geq 36.7)$ & $39.7(-178.7,258.1)$ & $0.2(-1.2,1.7)$ & $-0.9(-2.0,0.2)$ & $0.0(-0.2,0.2)$ & $1.9(-4.6,8.4)$ \\
\hline p-trend & 0.40 & 0.74 & 0.20 & 0.53 & 0.47 \\
\hline \multicolumn{6}{|l|}{ mCMHP } \\
\hline $1 \mathrm{st}(\leq 4.21)$ & Ref. & Ref. & Ref. & Ref. & \\
\hline 2nd (4.22 - 11.3) & $-201.7(-372.7,-30.7)^{* *}$ & $-1.1(-2.2,0.0)$ & $-0.2(-1.1,0.7)$ & $0.0(-0.1,0.1)$ & $-1.4(-6.8,4.0)$ \\
\hline $3 r d(11.4-30.0)$ & $-70.0(-256.6,118.7)$ & $-0.4(-1.6,0.8)$ & $-0.2(-1.2,0.9)$ & $0.0(-0.1,0.2)$ & $2.1(-4.9,9.1)$ \\
\hline 4th $(\geq 30.03)$ & $44.2(-196.7,285.1)$ & $-0.5(-1.9,1.0)$ & $-0.8(-2.0,0.3)$ & $0.1(-0.1,0.4)$ & $1.3(-6.2,8.8)$ \\
\hline p-trend & 0.68 & 0.38 & 0.19 & 0.14 & 0.65 \\
\hline \multicolumn{6}{|l|}{ High Molecular Weight } \\
\hline \multicolumn{6}{|l|}{$\mathrm{mOP}$} \\
\hline 1 st $(\leq-0.110)$ & Ref. & Ref. & Ref. & Ref. & Ref. \\
\hline 2nd (-0.111--0.0563) & $-215.4(-387.1,-43.7)^{* *}$ & $-0.71(-1.8,0.4)$ & $-0.11(-1.1,0.8)$ & $0.0(-0.2,0.1)$ & $5.2(-9.9,-0.4)^{*}$ \\
\hline 3rd (-0.0564 - 0.022) & $-75.3(-283.3,132.6)$ & $-0.3(-1.4,0.8)$ & $-0.5(-1.5,0.5)$ & $0.0(-0.1,0.2)$ & $-2.5(-7.7,2.7)$ \\
\hline
\end{tabular}


Table 3 Associations between quartiles of maternal urinary BPA and phthalate concentrations and mean change in birth outcomes (Continued)

\begin{tabular}{llllll}
\hline 4th $(\geq 0.024)$ & $-81.8(-251.7,88.0)$ & $0.12(-0.9,1.1)$ & $-0.74(-1.7,0.2)$ & $-0.1(-0.2,0.1)$ & $-4.9(-10.0,0.3)$ \\
p-trend & 0.30 & 0.91 & 0.11 & 0.40 & 0.11 \\
mNP & & & & \\
1st $(\leq-0.079)$ & Ref. & Ref. & Ref. & Ref. \\
2nd $(-0.0789--0.0006)$ & $-87.4(-258.8,83.9)$ & $-0.4(-1.5,0.6)$ & $0.4(-0.5,1.3)$ & $0.0(-0.1,0.2)$ & $-2.9(-7.5,1.7)$ \\
3rd $(-0.0005-0.067)$ & $53.9(-126.1,233.9)$ & $0.7(-0.5,1.8)$ & $0.1(-0.9,1.0)$ & $0.0(-0.2,0.1)$ & $-4.0(-9.0,1.0)$ \\
4th $(\geq 0.074)$ & $-149.8(-327.4,27.8)$ & $-0.1(-1.2,0.9)$ & $-0.1(-1.0,0.8)$ & $-0.1(-0.2,0.1)$ & $-\mathbf{- 7 . 0}(-1 \mathbf{2 . 3}, \mathbf{- 1 . 6}) * *$ \\
p-trend & 0.30 & 0.95 & 0.98 & 0.40 & $\mathbf{0 . 0 2}$ \\
\hline
\end{tabular}

NOTE: Significant findings are in boldface

Abbreviations: $B W$ birth weight (grams), $B L$ birth length (centimeters), $H C$ head circumference (centimeters), $P I$ Ponderal Index (grams/centimeters ${ }^{3}$ ), $G A$ gestational age (days), $m M P$ monomethyl phthalate, $m E P$ monoethyl phthalate, $m E H P$ monoethylhexyl phthalate, $m E O H P$ mono-(2-ethyl-5-oxohexyl) phthalate, $m E C P P$ mono(5-carboxy-2-ethylpentyl) phthalate, $m C M H P$ mono-[(2-carboxymethyl)hexyl] phthalate, $m O P$ mono-n-octyl phthalate, $m N P$ monoisononyl phthalate

Models were adjusted for creatinine ( $\mathrm{ng} / \mathrm{mL})$, age (years), race/ethnicity, BMI (kg/m2), education, cotinine (ng/mL), alcohol, conditional parity, infant gender, chemical ${ }^{*}$ gender, paternal chemicals

${ }^{*} p<0.05{ }^{* *} p \leq 0.01$

mECPP and gestational age, and $\mathrm{mCHP}$ with birth weight and gestational age. Furthermore, we found the $2^{\text {nd }}$ quartiles of maternal mMP and mOP to be associated with a 5 day shorter length of gestation and a 178-215 g lowered birth weight. Similarly, the $4^{\text {th }}$ quartile of paternal $\mathrm{mCHP}$ was associated with the longest increase in gestational age and the largest increase in birth weight; this pattern was not observed for every birth size and gestational age association. Even with such large reductions in birth weight, there was no hint of IUGR estimated by the Ponderal Index proxy.

Overall, urinary chemical concentrations in this study population were lower than those reported for other U.S. populations. For example, in our analysis cohort, preconception urine concentrations of BPA had a geometric mean of $0.38 \mathrm{ng} / \mathrm{mL}(95 \% \mathrm{CI}=0.31-0.45)$ for females and 0.59 (95\% CI $=0.49-0.71$ ) for male partners, whereas an analysis of urine samples from a subset of the National Health and Nutrition Examination Survey (NHANES) reported a geometric mean BPA of $1.74(95 \% \mathrm{CI}=1.55-1.95), 1.97(95 \% \mathrm{CI}=1.80-2.16)$, and $1.73(95 \% \mathrm{CI}=1.60-1.87) \mu \mathrm{g} / \mathrm{L}$ for females and 2.09 (95\% CI $=1.92-2.28), 2.20(95 \% \mathrm{CI}=2.01-2.41)$, and $1.94(95 \% \mathrm{CI}=1.82-2.07) \mu \mathrm{g} / \mathrm{L}$ for males, during the 2005-2006, 2007-2008, and 2009-2010 study periods, compared with our analysis cohort for which data was also collected during the 2005-2009 period of time [36].

We are currently unaware of any previously published work that has focused on preconception exposure to $\mathrm{BPA}$ and phthalates as it relates to birth size precluding a more complete interpretation of our findings. Our findings are also limited by reliance on a single spot urine collected at the time the couples began trying for pregnancy. However, despite the low-to-moderate intraclass correlation coefficients of EDCs (0.10-0.51) across pregnancy [37], a single spot urine has the ability to be predictive of exposure ranging from weeks to months $[38,39]$. Therefore our preconception urine samples of BPA and phthalates may reflect chemical levels during conception and possibly the first few weeks of pregnancy; a well-established critical window of fetal growth and development. This assumption is further supported by the concept of exposures to these non-persistent chemicals being continual on a daily basis [40-42]. Still, reliance on a single spot urine, whether collected prior to conception or during pregnancy, may not adequate characterize fetal exposure if one assumes changes in routes of exposures during these sensitive windows at any time, or if the many physiological changes required to support and maintain pregnancy affect internal doses and exposure quantification. Ideally, repeated samples within and across sensitive windows should be a part of future research methods to enable empirical assessment of exposure misclassification among other related considerations.

Furthermore, our study is strengthened by our assessment of paternal contribution to birth outcomes. Few epidemiological studies have been centered on paternal and/ or couples' non-occupational exposure to environmental chemicals as it relates to birth outcomes-none of which investigated BPA or phthalates. Nevertheless, previous analyses of maternal and paternal preconception exposures to persistent chemicals such as polybrominated diphenyl ethers and polychlorinated biphenyls and observed similar reductions in birth weight (21 to $195 \mathrm{~g}$ ) [19], as did trace elements such as cesium, tungsten and uranium for birth weight $(1.11$ to $1.30 \mathrm{~cm})$ and length $(1.07$ to $1.22 \mathrm{~cm})$ [43]. Additionally, large effect estimates of phthalates on birth weight (-177 to $-215 \mathrm{~g}$ ) resemble a smoking during pregnancy effect $[44,45]$.

Still, cautious interpretation of results is warranted, given the potential for competing risks since this analysis 
Table 4 Associations between quartiles of paternal urinary BPA and phthalate concentrations and mean change in birth outcomes

\begin{tabular}{|c|c|c|c|c|c|}
\hline & BW (g) & $\mathrm{BL}(\mathrm{cm})$ & $\mathrm{HC}(\mathrm{cm})$ & $\mathrm{PI}\left(\mathrm{g} / \mathrm{cm}^{3}\right)$ & GA (days) \\
\hline Chemical quartiles (ng/mL range) & $\beta(95 \% \mathrm{Cl})$ & $\beta(95 \% \mathrm{Cl})$ & $\beta(95 \% \mathrm{Cl})$ & $\beta(95 \% \mathrm{Cl})$ & $\beta(95 \% \mathrm{Cl})$ \\
\hline \multicolumn{6}{|l|}{ BPA } \\
\hline 1 st $(\leq 0.231)$ & Ref. & Ref. & Ref. & Ref. & Ref. \\
\hline 2nd (0.234 - 0.501) & $102.00(-93.35,297.96)$ & $0.80(-0.24,1.84)$ & $0.59(-0.33,1.50)$ & $-0.07(-0.20,0.07)$ & $2.34(-3.50,8.18)$ \\
\hline 3rd (0.511- 1.13) & $85.00(-105.69,276.23)$ & $0.95(-0.13,2.03)$ & $0.30(-0.62,1.22)$ & $-0.10(-0.23,0.03)$ & $2.48(-3.20,8.15)$ \\
\hline 4th $(\geq 1.14)$ & $178.53(-14.88,371.94)$ & $1.35(0.25,2.45)^{*}$ & $0.44(-0.45,1.33)$ & $-0.09(-0.26,0.07)$ & $2.44(-4.01,8.90)$ \\
\hline $\mathrm{p}$-trend & 0.07 & 0.02 & 0.34 & 0.25 & 0.44 \\
\hline \multicolumn{6}{|l|}{ DEHP Metabolites } \\
\hline \multicolumn{6}{|l|}{ mEHP } \\
\hline 1 st $(\leq-1.44)$ & Ref. & Ref. & Ref. & Ref. & Ref. \\
\hline 2nd $(-1.38-1.23)$ & $-191.93(-381.61,-2.25)^{*}$ & $-0.59(-1.62,0.45)$ & $-0.76(-1.64,0.11)$ & $-0.08(-0.21,0.06)$ & $0.64(-4.18,5.46)$ \\
\hline 3rd $(1.253-5.26)$ & $-130.56(-304.25,43.13)$ & $-0.11(-1.06,0.84)$ & $-0.38(-1.19,0.43)$ & $-0.08(-0.19,0.04)$ & $3.29(-1.31,7.9)$ \\
\hline 4th $(\geq 5.42)$ & $1.61(-176.84,180.06)$ & $-0.28(-1.36,0.8)$ & $-0.35(-1.23,0.52)$ & $0.03(-0.1,0.16)$ & $0.92(-4.35,6.18)$ \\
\hline p-trend & 0.99 & 0.61 & 0.43 & 0.61 & 0.73 \\
\hline \multicolumn{6}{|l|}{ mEOHP } \\
\hline 1 st $(\leq 3.04)$ & Ref. & Ref. & Ref. & Ref. & Ref. \\
\hline 2nd (3.06 - 6.93) & $-66.65(-264.08,130.78)$ & $-0.14(-1.39,1.1)$ & $-0.45(-1.45,0.55)$ & $-0.02(-0.18,0.13)$ & $7.23(2.36,12.1)^{* *}$ \\
\hline 3rd (6.94 - 17.7) & $-48.23(-266.56,170.09)$ & $-0.09(-1.41,1.22)$ & $-0.55(-1.49,0.4)$ & $-0.02(-0.19,0.14)$ & $5.13(0.02,10.25)^{*}$ \\
\hline 4th $(\geq 17.8)$ & $-65.30(-317.61,187.01)$ & $-0.58(-2.04,0.88)$ & $-0.56(-1.56,0.44)$ & $0.05(-0.1,0.2)$ & $3.22(-1.96,8.4)$ \\
\hline p-trend & 0.60 & 0.42 & 0.27 & 0.51 & 0.22 \\
\hline \multicolumn{6}{|l|}{ mECPP } \\
\hline 1 st $(\leq 8.53)$ & Ref. & Ref. & Ref. & Ref. & Ref. \\
\hline 2nd (8.60 - 20.2) & $-9.91(-224.03,204.22)$ & $-0.33(-1.83,1.17)$ & $-0.37(-1.29,0.55)$ & $0.06(-0.15,0.27)$ & $7.33(1.95,12.71)^{* *}$ \\
\hline 3rd (20.3 - 46.2) & $-13.26(-217.02,190.49)$ & $-0.18(-1.55,1.19)$ & $-0.15(-1.18,0.89)$ & $0.00(-0.22,0.21)$ & $5.08(-0.57,10.74)$ \\
\hline 4th $(\geq 46.3)$ & $7.90(-235.19,250.98)$ & $-0.77(-2.56,1.03)$ & $-0.35(-1.4,0.69)$ & $0.14(-0.07,0.35)$ & $6.38(0.26,12.5)^{*}$ \\
\hline p-trend & 0.95 & 0.37 & 0.51 & 0.18 & 0.04 \\
\hline \multicolumn{6}{|l|}{ High Molecular Weight } \\
\hline \multicolumn{6}{|l|}{$\mathrm{mCHP}$} \\
\hline 1 st $(\leq-0.0061)$ & Ref. & Ref. & Ref. & Ref. & Ref. \\
\hline 2nd $(-0.006-0.003)$ & $45.51(-130.2,221.23)$ & $0.59(-0.42,1.59)$ & $-0.04(-0.88,0.8)$ & $-0.06(-0.18,0.06)$ & $3.22(-1.34,7.78)$ \\
\hline 3rd (0.0026 - 0.0145) & $147.16(-20.82,315.14)$ & $0.30(-0.71,1.31)$ & $0.45(-0.44,1.35)$ & $0.03(-0.10,0.15)$ & $2.65(-2.05,7.34)$ \\
\hline 4th $(\geq 0.0148)$ & $224.45(33.94,414.96)^{*}$ & $0.92(-0.13,1.98)$ & $-0.52(-1.32,0.29)$ & $0.03(-0.10,0.16)$ & $7.01(2.16,11.86)^{* *}$ \\
\hline $\mathrm{p}$-trend & 0.02 & 0.08 & 0.33 & 0.65 & 0.00 \\
\hline \multicolumn{6}{|l|}{$\mathrm{mOP}$} \\
\hline 1 st $(\leq-0.115)$ & Ref. & Ref. & Ref. & Ref. & Ref. \\
\hline 2nd (-0.114--0.0489) & $-173.71(-347.54,0.11)$ & $-1.22(-2.33,-0.12)^{*}$ & $-0.52(-1.32,0.29)$ & $0.06(-0.09,0.2)$ & $-1.08(-5.82,3.67)$ \\
\hline 3rd (-0.0475-0.028) & $-67.62(-257.73,122.49)$ & $0.21(-0.89,1.3)$ & $0.26(-0.62,1.13)$ & $-0.08(-0.20,0.04)$ & $-4.07(-9.04,0.89)$ \\
\hline 4th $(\geq 0.029)$ & $-64.61(-243.21,113.99)$ & $-0.54(-1.6,0.52)$ & $0.17(-0.77,1.11)$ & $0.00(-0.13,0.13)$ & $-1.29(-6.13,3.56)$ \\
\hline p-trend & 0.48 & 0.32 & 0.72 & 0.97 & 0.60 \\
\hline
\end{tabular}

NOTE: Significant findings are in boldface

Abbreviations: $B W$ birth weight (grams), $B L$ birth length (centimeters), $H C$ head circumference (centimeters), $P I$ Ponderal Index (grams/centimeters ${ }^{3}$ ), GA gestational age (days), BPA bisphenol (A), $M E H P$ monoethylhexyl phthalate, $m E O H P$ mono-(2-ethyl-5-oxohexyl) phthalate, $m E C P P$ mono-(5-carboxy-2-ethylpentyl) phthalate, mCHP monocyclohexyl phthalate, $\mathrm{MOP}$ mono-n-octyl phthalate

Models were adjusted for creatinine $(\mathrm{ng} / \mathrm{mL})$, age (years), race/ethnicity, BMI ( $\mathrm{kg} / \mathrm{m} 2)$, education, cotinine ( $\mathrm{ng} / \mathrm{mL})$, alcohol, conditional parity, infant gender, chemical* gender, maternal chemicals

${ }^{*} p<0.05{ }^{* *} p \leq 0.01$ 
was conditioned on having a live birth and EDCs have also been reported to be associated with couples' ability to conceive [46]. However, the potential change in effect estimates would be relatively small and adjusting for common causes of the outcomes and fetal loss can reduce negative bias [47]. We also acknowledge the potential for spurious findings, given the comparison of multiple outcomes and chemicals. However when considering type I error for this analysis, many of our findings were statistically significant at with $p$-values $\leq 0.01$, which is a much smaller chance of falsely rejecting the null hypothesis of no mean change in birth outcomes per quartile increase of urinary chemical concentration, compared with the lowest quartile of preconception chemical. Imputation improved our precision, in that significance was lower in our initial analyses without imputation (data not shown). We also dichotomized chemicals ( $\mathrm{mCHP}$ and $\mathrm{mOP}$ ) with a high percentage of concentrations below the LOD at or below the $75^{\text {th }}$ percentile, and observed similar results as when modeling machine observed concentrations suggesting possible low dose effects. Despite these added analytic steps, cautious interpretation is needed in the interpretation of our findings as the findings await corroboration in light of these and other study limitations such as a relatively small cohort of infants and unknown birth outcomes for couples exiting the study before delivery.

Furthermore, the presence of many low-level chemical associations ( $2^{\text {nd }}$ and $3^{\text {rd }}$ quartiles) with birth size may not simply be explained as the result of limited sample size or overestimating the effect of urinary biomarkers of exposure in light of exposure misclassification. A growing body of evidence suggests that the endocrine system is sensitive to low-dose effects of various chemicals. Furthermore, animal studies of EDCs that act as antiandrogens or estrogen have shown that low-dose effects is not only chemical specific but varies by endpoint as well and may have global dynamic effects on cells, tissues and organs [48-50].

While the biological explanation behind these findings is not clearly understood, early pregnancy maternal exposures to EDCs have been associated with oxidative damage in rats, sheep and humans [51], and oxidative stress has been shown to play a role in intrauterine growth restriction (IUGR) [52, 53], and measures of fetal anthropometry at birth have been established as proxies for the assessment of IUGR. A previous analysis of phthalates and oxidative stress among the present cohort observed an increase in oxidative stress biomarker 8-hydroxy-2'-deoxyguanosine, with increased urinary concentrations of select phthalate metabolites [54]. We also consider the role of paternal exposures [55] found male urinary concentrations of select phthalate metabolites to be associated with diminished fecundity as measured by a longer time-to-pregnancy (TTP), although female urinary phthalate exposures were not associated with a longer TTP. DNA methylation is also suspected to affect select growth genes as a result of first trimester maternal phthalate exposure [56]. Animal studies suggest that DNA methylation may play a role in short-lived EDCs transgenerational epigenetic effects, which result in adverse reproductive outcomes in later offspring generations [57, 58]. A recent study of male mice exposed to dioxin found that even when mated with non-exposed female mice, multiple subsequent generations presented with reduced fertility and spontaneous preterm birth [59]. Additionally, male offspring of mice in one study had increased spermatogenic cell apoptosis and differential DNA methylation regions in the offspring sperm were consistent with a specific exposure lineage back to the original exposure of the first generation male mouse [60].

\section{Conclusions}

To our knowledge, this study represents an initial attempt to utilize a couple-based exposure design to assess the relation between maternal and paternal preconception urinary concentrations of BPA and phthalates and infant gestation and birth size. In the context of an observational design and exploratory analytic strategy, we observed some evidence that BPA and some but not all phthalates were associated with shorter gestations and smaller infants in relation to maternal exposure, but longer gestations and larger infants in relation to paternal exposures. Collectively, the findings underscore the importance of couple based designs for assessing the reproductive and/ or developmental toxicity of environmental phenols and other endocrine disrupting chemicals.

\section{Additional files}

Additional file 1: Distribution of birth outcomes by infant sex, LIFE Study, 2005-2009. (PDF 19 kb)

Additional file 2: Effect estimates of maternal urinary BPA, phthalate quartiles and mean change in birth outcomes, with no observed statistical significance, LIFE Study, 2005-2009. (DOCX 21 kb)

Additional file 3: Effect estimates of paternal urinary BPA, phthalate quartiles and mean change in birth outcomes, with no observed statistical significance, LIFE Study, 2005-2009. (DOCX 26 kb)

\section{Abbreviations}

BMI: Body mass index; BPA: Bisphenol A; DNA: Deoxyribose nucleic acid; EDCs: Endocrine disrupting chemicals; IUGR: Intrauterine growth restriction; LOD: Limit of detection; mBP: Mono-n-butyl phthalate; mBzP: Monobenzyl phthalate; mCHP: Monocyclohexyl phthalate; mCMHP: Mono-[(2carboxymethyl)hexyl] phthalate; mCPP: Mono(3-carboxypropyl) phthalate; mECPP: Mono-(5-carboxy-2-ethylpentyl) phthalate; mEHHP: Mono-(2-ethyl-5hydroxyhexyl) phthalate; mEHP: Monoethylhexyl phthalate; mEOHP: Mono-(2ethyl-5-oxohexyl) phthalate; mEP: Monoethyl phthalate; miBP: Monoisobutyl phthalate; mMP: Monomethyl phthalate; mNP: Monoisononyl phthalate; mOP: Mono-n-octyl phthalate; PI: Ponderal index; TTP: Time-to -pregnancy. 


\section{Competing interests}

The authors declare that they have no competing interests.

\section{Authors' contributions}

GMBL, MMS and RS contributed to conception and study design; KK and RS contributed to the acquisition of data; MMS and JMM performed data analysis; MMS, KLG, RS and GMBL contributed to interpretation of data; MMS and GMBL contributed to manuscript writing, and KLG, RS, JMM and KK critically revised the manuscript. All authors read and approved the final manuscript.

\section{Acknowledgments}

Funded by the National Institutes of Health, Intramural Research Program Eunice Kennedy Shriver National Institute of Child Health and Human Development (contracts N01-HD-3-3355; N01-HD-3-3356; NOH-HD-3-3358; HHSN27500001).

\section{Author details}

'Division of Intramural Population Health Research, Eunice Kennedy Shriver National Institute of Child Health and Human Development, National Institutes of Health, 6100 Executive Blvd, Rockville, MD 20852, USA. ${ }^{2}$ Division of Environmental Health Sciences, Wadsworth Center, New York State Department of Health and Department of Environmental Health Sciences, The University at Albany, Empire State Plaza, P.O. Box 509, Albany, NY, USA.

\section{Received: 13 May 2015 Accepted: 1 September 2015}

\section{Published online: 11 September 2015}

\section{References}

1. Program NT: Bisphenol A. In. National Institute of Envrionmental Health Sciences; 2010: 2.

2. Schettler T. Human exposure to phthalates via consumer products. Int J Androl. 2006;29(1):134-9.

3. Calafat AM, Ye X, Wong LY, Reidy JA, Needham LL. Exposure of the U.S. population to bisphenol A and 4-tertiary-octylphenol: 2003-2004. Environ Health Perspect. 2008, 116(1):39-44

4. Silva MJ, Barr DB, Reidy JA, Malek NA, Hodge CC, Caudill SP, Brock JW, Needham LL, Calafat AM. Urinary Levels of Seven Phthalate Metabolites in the U.S. Population from the National Health and Nutrition Examination Survey (NHANES) 1999-2000. Environ Health Perspect. 2004, 112(3):331-338

5. Woodruff TJ, Zota AR, Schwartz JM. Environmental chemicals in pregnant women in the United States: NHANES 2003-2004. Environ Health Perspect. 2011;119(6):878-85.

6. Peretz J, Vrooman L, Ricke WA, Hunt PA, Ehrlich S, Hauser R, et al. Bisphenol $a$ and reproductive health: update of experimental and human evidence, 2007-2013. Environ Health Perspect. 2014;122(8):775-86.

7. Cantonwine DE, Hauser R, Meeker JD. Bisphenol A and Human Reproductive Health. Expert Rev Obstet Gynecol. 2013;8(4):329-35.

8. Rochester JR. Bisphenol A and human health: a review of the literature. Reprod Toxicol. 2013;42:132-55.

9. Meeker JD, Ehrlich S, Toth TL, Wright DL, Calafat AM, Trisini AT, et al. Semen quality and sperm DNA damage in relation to urinary bisphenol A among men from an infertility clinic. Reprod Toxicol. 2010;30(4):532-9.

10. Ehrlich S, Williams PL, Missmer SA, Flaws JA, Ye X, Calafat AM, et al. Urinary bisphenol A concentrations and early reproductive health outcomes among women undergoing IVF. Hum Reprod. 2012;27(12):3583-92.

11. Mok-Lin E, Ehrlich S, Williams PL, Petrozza J, Wright DL, Calafat AM, et al. Urinary bisphenol A concentrations and ovarian response among women undergoing IVF. Int J Androl. 2010;33(2):385-93.

12. Ferguson KK, McElrath TF, Meeker JD. Environmental phthalate exposure and preterm birth. JAMA Pediatr. 2014;168(1):61-7.

13. Whyatt RM, Adibi JJ, Calafat AM, Camann DE, Rauh V, Bhat HK, et al. Prenatal di(2-ethylhexyl)phthalate exposure and length of gestation among an inner-city cohort. Pediatrics. 2009;124(6):e1213-20.

14. Cantonwine D, Meeker JD, Hu H, Sanchez BN, Lamadrid-Figueroa $\mathrm{H}_{\text {, }}$ Mercado-Garcia A, et al. Bisphenol a exposure in Mexico City and risk of prematurity: a pilot nested case control study. Environ Health. 2010;9:62.

15. Weinberger B, Vetrano AM, Archer FE, Marcella SW, Buckley B, Wartenberg D, et al. Effects of maternal exposure to phthalates and bisphenol A during pregnancy on gestational age. J Matern Fetal Neonatal Med: the official journal of the European Association of Perinatal Medicine, the Federation of Asia and
Oceania Perinatal Societies, the International Society of Perinatal Obstet. 2014;27(4):323-7.

16. Wolff MS, Engel SM, Berkowitz GS, Ye X, Silva MJ, Zhu C, et al. Prenatal phenol and phthalate exposures and birth outcomes. Environ Health Perspect. 2008;1 16(8):1092-7.

17. Snijder CA, Heederik D, Pierik FH, Hofman A, Jaddoe WW, Koch HM, et al. Fetal growth and prenatal exposure to bisphenol A: the generation R study. Environ Health Perspect. 2013;121(3):393-8.

18. Braun JM, Smith KW, Williams PL, Calafat AM, Berry K, Ehrlich S, et al. Variability of urinary phthalate metabolite and bisphenol A concentrations before and during pregnancy. Environ Health Perspect. 2012;120(5):739-45.

19. Robledo CA, Yeung E, Mendola P, Sundaram R, Maisog J, Sweeney AM, et al. Preconception Maternal and Paternal Exposure to Persistent Organic Pollutants and Birth Size: The LIFE Study. Environ Health Perspect. (123.1) 2015:88.

20. Miao M, Yuan W, Zhu G, He X, Li DK. In utero exposure to bisphenol-A and its effect on birth weight of offspring. Reprod Toxicol. 2011;32(1):64-8.

21. Vestergaard S, Nielsen F, Andersson A-M, Hjøllund NH, Grandjean P, Andersen HR, et al. Association between perfluorinated compounds and time to pregnancy in a prospective cohort of Danish couples attempting to conceive. Hum Reprod. 2012;27(3):873-80.

22. Chapin RE, Robbins WA, Schieve LA, Sweeney AM, Tabacova SA, Tomashek KM Off to a good start: the influence of pre- and periconceptional exposures, parental fertility, and nutrition on children's health. Environ Health Perspect. 2003;112(1):69-78.

23. Buck Louis GM, Schisterman EF, Sweeney AM, Wilcosky TC, Gore-Langton $R E$, Lynch CD, et al. Designing prospective cohort studies for assessing reproductive and developmental toxicity during sensitive windows of human reproduction and development-the LIFE Study. Paediatr Perinat Epidemiol. 2011;25(5):413-24.

24. Lohman TG, Roche AF, Martorell R. Anthropometric standardization reference manual. Champaign, IL: Human Kinetics Books; 1988.

25. Buck Louis GM, Sundaram R, Schisterman EF, Sweeney AM, Lynch CD, Gore-Langton RE, et al. Heavy metals and couple fecundity, the LIFE study. Chemosphere. 2012;87(11):1201-7.

26. Zhang Z, Alomirah H, Cho HS, Li YF, Liao C, Minh TB, et al. Urinary bisphenol A concentrations and their implications for human exposure in several Asian countries. Environ Sci Technol. 2011:45(16):7044-50.

27. Guo Y, Alomirah H, Cho HS, Minh TB, Mohd MA, Nakata H, et al. Occurrence of phthalate metabolites in human urine from several Asian countries. Environ Sci Technol. 2011;45(7):3138-44

28. Bernert Jr JT, Turner WE, Pirkle JL, Sosnoff CS, Akins JR, Waldrep MK, et al. Development and validation of sensitive method for determination of serum cotinine in smokers and nonsmokers by liquid chromatography/ atmospheric pressure ionization tandem mass spectrometry. Clin Chem. 1997;43(12):2281-91.

29. Miller HC, Hassanein K. Diagnosis of impaired fetal growth in newborn infants. Pediatrics. 1971;48(4):511-22.

30. Schisterman EF, Vexler A, Whitcomb BW, Liu A. The limitations due to exposure detection limits for regression models. Am J Epidemiol. 2006;163(4):374-83.

31. Lubin JH, Colt JS, Camann D, Davis S, Cerhan JR, Severson RK, et al. Epidemiologic evaluation of measurement data in the presence of detection limits. Environ Health Perspect. 2004;112(17):1691-6.

32. Horton NJ, Kleinman KP. Much Ado about nothing. Am Stat. 2007;61 (1):79-90.

33. Schafer J. Analysis of incomplete multivariate data. New York: Chapman and Hall; 1997.

34. Swan SH. Environmental phthalate exposure in relation to reproductive outcomes and other health endpoints in humans. Environ Res. 2008;108(2):177-84.

35. Main KM, Mortensen GK, Kaleva MM, Boisen KA, Damgaard IN, Chellakooty M, et al. Human breast milk contamination with phthalates and alterations of endogenous reproductive hormones in infants three months of age. Environ Health Perspect. 2006;114(2):270-6.

36. Prevention CfDCa. Fourth Report on Human Exposure to Environmental Chemicals, Updated Tables, (February, 2015). Atlanta, GA: U.S. Department of Health and Human Services, Centers for Disease Control and Prevention; 2015.

37. Fisher M, Arbuckle TE, Mallick R, LeBlanc A, Hauser R, Feeley M, et al. "Bisphenol A and phthalate metabolite urinary concentrations: Daily and across pregnancy variability." Journal of Exposure Science and Environmental Epidemiology. (25.3) 2015:231-9. 
38. Mahalingaiah S, Meeker JD, Pearson KR, Calafat AM, Ye X, Petrozza J, et al. Temporal variability and predictors of urinary bisphenol A concentrations in men and women. Environ Health Perspect. 2008;116(2):173-8.

39. Teitelbaum SL, Britton JA, Calafat AM, Ye X, Silva MJ, Reidy JA, et al. Temporal variability in urinary concentrations of phthalate metabolites, phytoestrogens and phenols among minority children in the United States. Environ Res. 2008;106(2):257-69.

40. Koch HM, Drexler $\mathrm{H}$, Angerer J. An estimation of the daily intake of di(2-ethylhexyl)phthalate (DEHP) and other phthalates in the general population. Int J Hyg Environ Health. 2003;206(2):77-83.

41. Wittassek M, Heger W, Koch HM, Becker K, Angerer J, Kolossa-Gehring M. Daily intake of di(2-ethylhexyl)phthalate (DEHP) by German children - A comparison of two estimation models based on urinary DEHP metabolite levels. Int J Hyg Environ Health. 2007;210(1):35-42.

42. Wittassek M, Wiesmuller GA, Koch HM, Eckard R, Dobler L, Muller J, et al. Internal phthalate exposure over the last two decades-a retrospective human biomonitoring study. Int J Hyg Environ Health. 2007;210(3-4):319-33.

43. Bloom MS, Buck Louis GM, Sundaram R, Maisog JM, Steuerwald AJ, Parsons PJ. Birth outcomes and background exposures to select elements, the Longitudinal Investigation of Fertility and the Environment (LIFE). Environ Res. 2015;138C:118-29.

44. Cliver SP, Goldenberg RL, Cutter GR, Hoffman HJ, Davis RO, Nelson KG. The effect of cigarette smoking on neonatal anthropometric measurements. Obstet Gynecol. 1995;85(4):625-30.

45. Wang X, Zuckerman B, Pearson C, et al. MAternal cigarette smoking, metabolic gene polymorphism, and infant birth weight. JAMA. 2002;287(2):195-202.

46. Velez MP, Arbuckle TE, Fraser WD. Maternal exposure to perfluorinated chemicals and reduced fecundity: the MIREC study. Hum Reprod. 2015:30(3):701-9.

47. Liew Z, Ritz B, Rebordosa C, Lee PC, Olsen J. Acetaminophen use during pregnancy, behavioral problems, and hyperkinetic disorders. JAMA Pediatr. 2014;168(4):313-20.

48. Vandenberg LN, Colborn T, Hayes TB, Heindel JJ, David R, Jacobs J, et al. Hormones and endocrine-disrupting chemicals: low-dose effects and nonmonotonic dose responses. Endocr Rev. 2012;33(3):378-455.

49. Welshons W, Nagel SC, vom Saal FS. Large effects from small exposures. III. Endocrine mechanisms mediating effects of bisphenol A at levels of human exposure. Endocrinology. 2006;147(6 Suppl):S56-69.

50. Cabaton NJ, Canlet C, Wadia PR, Tremblay-Franco M, Gautier R, Molina J, et al. Effects of low doses of bisphenol A on the metabolome of perinatally exposed CD-1 mice. Environ Health Perspect. 2013;121(5):586-93.

51. Padmanabhan V, Siefert K, Ransom S, Johnson T, Pinkerton J, Anderson L, et al. Maternal bisphenol-A levels at delivery: a looming problem? J Perinatol. 2008;28(4):258-63.

52. Kamath U, Rao G, Kamath SU, Rai L. Maternal and fetal indicators of oxidative stress during intrauterine growth retardation (IUGR). Indian J Clin Biochem. 2006;21(1):111-5.

53. Biri A, Bozkurt N, Turp A, Kavutcu M, Himmetoglu O, Durak I. Role of oxidative stress in intrauterine growth restriction. Gynecol Obstet Invest. 2007;64(4):187-92.

54. Guo Y, Weck J, Sundaram R, Goldstone AE, Louis GB, Kannan K. Urinary concentrations of phthalates in couples planning pregnancy and its association with 8-hydroxy-2'-deoxyguanosine, a biomarker of oxidative stress: longitudinal investigation of fertility and the environment study. Environ Sci Technol. 2014;48(16):9804-11.

55. Buck Louis GM, Sundaram R, Sweeney AM, Schisterman EF, Maisog J, Kannan K. Urinary bisphenol A, phthalates, and couple fecundity: the Longitudinal Investigation of Fertility and the Environment (LIFE) Study. Fertil Steril. 2014;101(5):1359-66.

56. LaRocca J, Binder AM, McElrath TF, Michels KB. The impact of first trimester phthalate and phenol exposure on IGF2/H19 genomic imprinting and birth outcomes. Environ Res. 2014;133:396-406.

57. Singh S, Li SS. Epigenetic effects of environmental chemicals bisphenol a and phthalates. Int J Mol Sci. 2012;13(8):10143-53.

58. Kundakovic M, Champagne FA. Epigenetic perspective on the developmental effects of bisphenol A. Brain Behav Immun. 2011;25(6):1084-93.
59. Bruner-Tran KL, Ding T, Yeoman KB, Archibong A, Arosh JA, Osteen KG. Developmental exposure of mice to dioxin promotes transgenerational testicular inflammation and an increased risk of preterm birth in unexposed mating partners. PLoS One. 2014;9(8):e105084.

60. Manikkam M, Guerrero-Bosagna C, Tracey R, Haque MM, Skinner MK. Transgenerational actions of environmental compounds on reproductive disease and identification of epigenetic biomarkers of ancestral exposures. PLoS One. 2012;7(2):e31901.

\section{Submit your next manuscript to BioMed Central and take full advantage of:}

- Convenient online submission

- Thorough peer review

- No space constraints or color figure charges

- Immediate publication on acceptance

- Inclusion in PubMed, CAS, Scopus and Google Scholar

- Research which is freely available for redistribution 